\title{
The Earth Is the Best Place to Live
}

\author{
J. T. Trevors
}

Published online: 13 October 2009

(C) Springer Science + Business Media B.V. 2009

The Earth is still the best planet to live despite our current problems/challenges of human population growth, total global pollution, global climate change, pandemics, wars, hunger and intolerance, to name a few examples. The universe has to be billions of years old to have sufficient time to produce the elements required for living organisms and their evolution. One would think that all humans would therefore take better care of the only known outpost of life in the universe. The Earth is the correct distance from our sun to maintain water in its liquid state (and gaseous and solid states) necessary for living organisms. Water has a low viscosity, high melting point, high boiling point and can act as a hydrogen donor and acceptor. Water can buffer against shifts in temperature. Water floats when it freezes and becomes ice, and reaches its maximum density at $4^{\circ} \mathrm{C}$ not at $0^{\circ} \mathrm{C}$. These characteristics have immense importance for aquatic life.

The size and mass of the Earth are correct for life. A small planet does not have sufficient gravity to hold an atmosphere such as ours. If the Earth was larger, the atmosphere would be denser and restrict light necessary for photosynthesis. No photosynthesis means no life as we know it on the Earth. The Earth is as good as it gets for the continued survival of all species, if humans

J. T. Trevors $(\bowtie)$

School of Environmental Sciences, University of Guelph, Guelph, Ontario, Canada N1G 2W1

e-mail: jtrevors@uoguelph.ca simply reduce human population growth and the total pollution of the planet. This will require international cooperation and the efforts of all people, especially in the affluent developed countries that over pollute and over consume. The affluent countries must also provide the resources to assist less affluent countries with their basic human needs and rights. This is all doable if humans simply redirect efforts from conflicts and wars to international cooperation.

The already overpopulated Earth with several billion too many people, consuming and polluting and entangled in complex conflicts for limited resources has no rationale present and future within the current paradigm. There is no future in conflicts, wars, violations of basic human rights and needs, competition, discrimination, lack of public infrastructure, hunger and poverty all entangled within pollution and global climate change. The challenges/problems that we currently face can quickly turn into global crises (e.g. global warming, pandemics, overpopulation, food shortages) if the correct international actions are not implemented. The Earth is our only outpost. We can not travel quickly to other planetary locations and sustain life as we know it. Our correct choices are conservation, environmental protection, planned and managed human population control, international cooperation, evolve modern democracies and stable governments, education, basic human rights and needs and too all strive for the sanctity of life and humanity. The best way to halt total global pollution and climate change is to reduce total global pollution and the factors that cause climate change and overpopulation. What a wonderful world it will be. 